\title{
The common anesthetic, sevoflurane, induces apoptosis in A549 lung alveolar epithelial cells
}

\author{
GUI-HUA WEI ${ }^{1,2^{*}}$, JUAN ZHANG $^{3 *}$, DA-QING LIAO ${ }^{1}$, ZHUO LI $^{1}$, JING YANG $^{1}$, NAN-FU LUO $^{1}$ and YAN GU \\ ${ }^{1}$ Laboratory of Anesthesiology and Critical Care Medicine, West China Hospital, Sichuan University; \\ ${ }^{2}$ Department of Life Science and Technology, Southwest Jiaotong University; \\ ${ }^{3}$ Pharmaceutical Institute of Chengdu Diao Pharmaceutical Group, Chengdu, Sichuan 610041; \\ ${ }^{4}$ Pulmonary Division of the Affiliated Hospital of Inner Mongolia Medical University, \\ Huhhot, Inner Mongolia Autonomous Region 010050, P.R. China
}

Received May 16, 2013; Accepted November 4, 2013

DOI: $10.3892 / \mathrm{mmr} .2013 .1806$

\begin{abstract}
Lung alveolar epithelial cells are the first barrier exposed to volatile anesthetics, such as sevoflurane, prior to reaching the targeted neuronal cells. Previously, the effects of volatile anesthetics on lung surfactant were studied primarily with physicochemical models and there has been little experimental data from cell cultures. Therefore it was investigated whether sevoflurane induces apoptosis of A549 lung epithelial cells. A549 cells were exposed to sevoflurane via a calibrated vaporizer with a $21 / \mathrm{min}$ flow in a gas-tight chamber at $37^{\circ} \mathrm{C}$. The concentration of sevoflurane in Dulbecco's modified Eagle's medium was detected with gas chromatography. Untreated cells and cells treated with $2 \mu \mathrm{M}$ daunorubicin hydrochloride (DRB) were used as negative and positive controls, respectively. Apoptosis factors, including the level of ATP, apoptotic-bodies by terminal deoxynucleotidyl transferase-mediated dUTP nick end labeling (TUNEL) assay, DNA damage and the level of caspase 3/7 were analyzed. Cells treated with sevoflurane showed a significant reduction in ATP compared with untreated cells. Effects in the DRB group were greater than in the sevoflurane group. The difference of TUNEL staining between the sevoflurane and untreated groups was statistically significant. DNA degradation was observed in the sevoflurane and DRB groups, however this was not observed in the untreated group. The sevoflurane and DRB groups induced increased caspase $3 / 7$ activation compared with untreated cells. These results suggest that sevoflurane induces apoptosis in A549 cells. In conclusion, 5\% sevoflurane
\end{abstract}

Correspondence to: Mrs. Gui-Hua Wei, Laboratory of Anesthesiology and Critical Care Medicine, West China Hospital, Sichuan University, No. 37 Guo Xue Xiang, Chengdu, Sichuan 610041, P.R. China

E-mail: mochoutianxia@tom.com

*Contributed equally

Key words: sevoflurane, lung alveolar epithelial cells, A549 cells, apoptosis, ATP, terminal deoxynucleotidyl transferase-mediated dUTP nick end labeling staining, DNA damage, caspase 3/7 induced apoptosis of A549 lung alveolar epithelial cells, which resulted in decreased cell viability, increased apoptotic bodies, impaired DNA integrality and increased levels of caspase 3/7.

\section{Introduction}

Over the past decade, increasing evidence has indicated that adverse reactions are associated with volatile anesthetics $(1,2)$. Xie et al observed that neurodegenerative disorders, including Alzheimer's and Parkinson's diseases, may be accelerated by volatile anesthesia following long surgery (3-5). More recently, they showed that anesthesia with sevoflurane for $6 \mathrm{~h}$ induced caspase activation and apoptosis, altered amyloid precursor protein (APP) processing and increased amyloid- $\beta$ levels in the brain tissue of transgenic mice (6). Inhalation anesthetics also led to pronounced immunosuppression by reducing the activity of the natural killer cells $(7,8)$, peripheral leukocytes and T lymphocytes (9). Matsuoka et al (10) observed that sevoflurane and isoflurane induced apoptosis in human peripheral lymphocytes in a dose- and time-dependent manner and that apoptosis was strictly associated with overproduction of reactive oxygen species (ROS) mediated by mitochondria $(10,11)$.

Over the past few years, the majority of studies have been focused on the exact mechanism of action of volatile anesthetics using physicochemical models; however, precise information of the effects on cell culture model systems in vitro remains unclear, particularly the potent negative effect on lung alveolar cells. During inhalation of anesthesia, lung epithelial cells are the first barrier directly exposed to volatile anesthetics prior to reaching the target neuronal cells. Type II pneumocytes are the primary producers of pulmonary surfactant, a liquid film that consists of $\sim 90 \%$ liquid and $\sim 10 \%$ proteins (12). An important function of type II pneumocytes is that they are the alveolar progenitor cells responsible for normal tissue turnover and restoration of alveoli following lung injury $(13,14)$. The A549 human lung carcinoma cell line, which is sensitive to harmful agents, is widely accepted as a model for in vitro investigations of type II alveolar pneumocytes (15).

There are well-documented examples that indicate that halothane reduces the production of phophatidylcholine, which is the major surfactant component of A549 pulmonary cells, following 
treatment with $1.5-3 \mathrm{mM}$ concentrations in vitro $(16,17)$. Studies also observed that halothane decreased lung cell viability, impaired DNA integrality and provoked stress-induced apoptosis by reduction of Bcl-2 expression of the mitochondrial apoptotic pathway (18). However, the effect of sevoflurane, halothane's parent molecule on the action the lung-type 2 alveolar pneumocytes is obscure and not yet completely clear. Numerous pathophysiological mechanisms have been implicated in the development of cell damage; however, the exact cascade leading to sevoflurane-mediated development is unclear.

Sevoflurane, the most popular anesthetic used daily, as with halothane, was hypothesized to induce A549 lung alveolar cell apoptosis in vitro. Apoptosis is the predominant mechanism regulating immunological homeostasis and the termination of surgical injury-induced inflammation on lung epithelial cells $(19,20)$. However, to avoid these side effects and evaluate cellular injury, identification of the various apoptotic changes in sevoflurane-treated lung cells is required. Thus, the current study aimed to evaluate the apoptotic changes on sevoflurane-treated A549 human lung alveolar cells and to assess the effects of $1 \mathrm{mM}$ sevoflurane on apoptotic-bodies, DNA damage and caspase 3/7, the most important indicators of apoptosis.

\section{Materials and methods}

Cell culture. All experiments were performed with A549 cells, a lung-derived human carcinoma cell line (no. CCL-185), obtained from our laboratory, maintaining the morphological and biochemical characteristics of type II pneumocytes (21). The cells were cultured in Dulbecco's modified Eagle's medium (DMEM; HyClone Laboratories Inc., South Logan, UT, USA), supplemented with $10 \%$ fetal bovine serum (HyClone Laboratories Inc.), $2 \mathrm{mM}$ glutamine, $100 \mathrm{U}$ penicillin and $100 \mu \mathrm{g} / \mathrm{ml}$ streptomycin (all Gibco Invitrogen Canada Inc., Burlington, ON, Canada). The cultures were equilibrated with humidified $5.0 \%(\mathrm{v} / \mathrm{v}) \mathrm{CO}_{2}$ in air at $37^{\circ} \mathrm{C}$ in a Series II Water $\mathrm{CO}_{2}$ Jacketed Incubator (Thermo Fisher Scientific Inc., Marietta, OH, USA).

Exposure to sevoflurane. A549 cells were exposed to 5\% (v/v) sevoflurane (Sevoflurane ${ }^{\circledR}$; Maruishi Pharmaceutical Co., Ltd., Osaka, Japan) by calibrated vaporizers (Datex-Ohmeda Inc., Madison, WI, USA) with a $21 / \mathrm{min}$ flow of $95 \%$ air and $5 \%$ $\mathrm{CO}_{2}$ using an anesthesia machine (Excel 210SE; Ohmeda Inc., Madison, WI, USA) for $2 \mathrm{~h}$ in a gas tight glass chamber, which was maintained at $37^{\circ} \mathrm{C}$ by electric-heated thermostatic water bath (ZHWY-110X30; Zhicheng Inc., Shanghai, China). Humidification was achieved with water evaporation inside the chamber. The sevoflurane concentration was a constant $5.0 \%(\mathrm{v} / \mathrm{v})$, which was detected with an infrared anesthetic gas module (M1026B; Philips Inc., Berlin, Germany). Simultaneously, a $60-\mathrm{mm}$ culture dish containing $5 \mathrm{ml}$ medium was used to measure the fluid concentrations of sevoflurane dissolved in the cell culture medium by gas chromatography (Agilent 4890D; Agilent Technologies Inc., Palo Alto, CA, USA) in the chamber of every experiment. The coefficient of sevoflurane in DMEM-gas was observed at $0.38 \pm 0.08$ by gas chromatography. The concentration of sevoflurane in DMEM was $1.0 \pm 0.1 \mathrm{mM}$, which was higher than those attained in the plasma of patients during administration of sevoflurane for general anesthesis. An untreated control group was obtained in a standard $95 \%$ air, $5 \% \mathrm{CO}_{2}$ incubator without anesthetic exposure. A positive control group was treated with $2 \mu \mathrm{M}$ daunorubicin hydrochloride (DRB; Sigma-Aldrich, St. Louis, MO, USA). Following treatment under the respective conditions at $37^{\circ} \mathrm{C}$ for $2 \mathrm{~h}$, cells were washed three times with phosphate-buffered saline and used in a number of experiments $24 \mathrm{~h}$ later.

Cell viability by adenosine triphoshpate (ATP) assay. The cells were seeded into a 96-microwell plate at a density of $1 \times 10^{4}$ cells/well. The activity of ATP was detected by Wallac Victor 21420 Multilabel Counter with Enliten ${ }^{\circledR}$ rLuciferase/Luciferin reagent kit (cat. no. FF2021; Promega Corporation, Madison, WI, USA). Wearing new, disposable gloves when preparing samples and performing the ATP assay was required. Untreated, DRB- and sevoflurane-treated cells were added, assuming $0.1 \mathrm{ml}$ reagent/well, mixed gently to avoid generating aerosols that may contaminate assay reagents and incubated at room temperature for $30 \mathrm{~min}$. When ATP was the limiting component in the luciferase reaction, the intensity of the emitted light was proportional to the concentration of ATP and the number of viable cells was assessed based on the quantity of ATP available.

Terminal deoxynucleotidyl transferase-mediated dUTP nick end labeling (TUNEL) staining. The histochemical TUNEL kit (cat. no. 1168409910; Roche Diagnostics, Mannheim, Germany) was used to detect apoptotic-bodies on A549 cells. The cells $\left(1 \times 10^{5}\right.$ cells $\left./ \mathrm{ml}\right)$ were cultured on sterile coverslips on 35-mm dish (Corning Inc., New York, NY, USA) overnight. Following treatment, cells were fixed with $4 \%$ paraformaldehyde and TUNEL was performed according to the manufacturer's instructions. TUNEL-positive cells were defined using a microscope (DP70; Olympus Corporation, Tokyo, Japan), which was equipped with a digital camera (BX51; Olympus Corporation). There were different numbers of dead cells that detached from the cover between the untreated, DRB and sevoflurane groups. In addition to cell counts, cell morphology was also examined. Cells with nuclear abnormalities, including chromatin compaction and clustering, fragmented nuclei, bi- and tri-nucleated cells that represent an apoptosis-like or necrotic-like cell, were counted. Data were received for the number of surviving cells due to the effect of sevoflurane, DRB and untreated control with CAST software (Revision 0.9.5; Olympus Danmark A/S, Ballerup, Denmark). The ratios of positively stained cells to total cells were calculated. Ten sites were selected at random for each slide for image analysis (Image-Pro Plus version 4.5.0.19; Media Cybernetics, Carlsbad, CA, USA). All examinations were performed by blinded observers. Furthermore, the values were obtained from three repeated experiments and ten images per experiment and the averages are presented as mean \pm standard deviation.

DNA isolation and electrophoresis. The cells were seeded into $60-\mathrm{mm}^{2}$ corning culture dishes at a density of $1 \times 10^{6}$ cells/dish. Following treatment, cells were collected and DNA isolation was performed using the cells/tissue genomic DNA extraction 
kit (cat. no. GK0121; Generay Biotech Co., Ltd., Shanghai, China), according to the manufacturer's instructions. DNA integrality in cells was analyzed by $0.8 \%$ agarose gel (Sigma-Aldrich) electrophoresis for $1 \mathrm{~h}$ at $80 \mathrm{~V}$. Visualization of DNA was analyzed by ethidium bromide fluorescence using UVP EC3 Imaging system (UVP Inc., Upland, CA, USA) with VisionWorks ${ }^{\circledR}$ Ls Image Acquisition and Analysis software (version 5.5.3; UVP Inc., Upland, CA, USA).

Analysis of caspases 3/7 activity. The cells were cultured in a 96-microwell plate at a density of $1 \times 10^{4}$ cells/well overnight. The groups of cells were then exposed to each pre-set condition and the activity of caspase $3 / 7$ was detected by Wallac Victor 21420 Multilabel Counter (PerkinElmer Inc., Wellesley, MA, USA) with caspase-Glo ${ }^{\circledR}$ 3/7 assay kit (cat. no. G8090; Promega Corporation) according to the manufacturer's instructions. Following treatment, $100 \mu$ l caspase 3/7 substrate was added to the cell suspension in each well. Following immediately mixing, the plate was incubated at room temperature for $30 \mathrm{~min}$. A 'no-cell' control, in addition to an untreated control to account for the signal generated from serum alone, was performed. The 'no-cell' control signal was subtracted from signals produced by the treated and untreated cells. The luminescent signal was recorded, which was proportional to the amount of caspase 3/7 activity present.

Statistical analysis. Each experiment was performed three times. Data are presented as the mean \pm standard deviation and analyzed using a one-way analysis of variance and Student-Newman-Keuls (SNK) test (non-parametric) for multiple comparisons. $\mathrm{P}<0.05$ was considered to indicate a statistically significant difference. All statistical analyses were performed by the software SPSS 15.0 for windows (SPSS, Inc., Chicago, IL, USA).

\section{Results}

Sevoflurane decreases cell viability as shown by an ATP assay. Apoptosis is a genetically determined active form of cell death that is essential under physiological and pathological conditions throughout the embryonic development and later life of multicellular organisms (22). Since ATP is an indicator of metabolically active cells, the number of viable cells may be assessed based on the quantity of ATP available. The ATP assay showed improved reproducibility and sensitivity compared with the MTT assay and is particularly useful for the measurement of viability with low cell numbers (23). Cells treated with sevoflurane showed a significant reduction in ATP (reduction, 51.3\%) compared with untreated cells $(\mathrm{P}<0.001, \mathrm{SNK})$. The reduction by the DRB group was more evident (reduction, $72 \%$ ) compared with the untreated group $(\mathrm{P}<0.001, \mathrm{SNK})$. These results were consistent with TUNEL staining of the remaining cell number which showed that A549 cells exposed to sevoflurane underwent programmed cell death (Fig. 1).

Sevoflurane inducing apoptotic body formation shown by TUNEL staining. According to the images, obtained by light microscopy with a digital camera, of the three groups, sevoflurane induced morphological changes in A549 cells; the
The level of ATP in cell

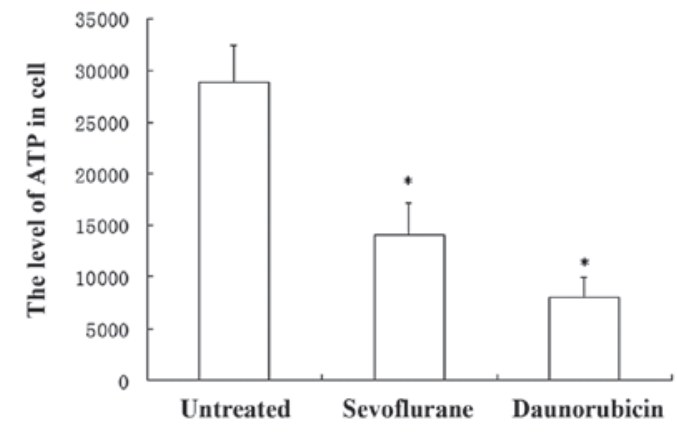

Figure 1. Sevoflurane reduces the intracellular level of ATP in A549 cells. The intracellular level of ATP in A549 cells of three groups: Untreated, 28914.1 \pm 3587.9 ; sevoflurane, $14074.1 \pm 3116.8$ and DRB, 8083.8 \pm 1833.2 . DRB and sevoflurane reduced ATP compared with the untreated group. The difference between the sevoflurane-treated and untreated groups was statistically significant $(\mathrm{P}<0.001, \mathrm{SNK})$ and the difference between the DRB and untreated groups was statistically significant $(\mathrm{P}<0.001, \mathrm{SNK})$. The data obtained from three experiments for each sample are presented. Data are shown as the mean \pm standard deviation. ${ }^{*} \mathrm{P}<0.05$, vs. the untreated group. ATP, adenosine triphosphate; DRB, daunorubicin hydrochloride; SNK, Student-Newman-Keuls.

cells became more rounded and detached from the dish. The number of detached cells in the sevoflurane group was greater compared with the untreated group, but less than the DRB group (data not shown).

The quantitative analysis of the effect of sevoflurane on A549 cells was evaluated by TUNEL staining. In apoptosis, cells became spherical, ballooned and dispersed into smaller groups and apoptotic-bodies were observed. In the three groups the proportion of cells with apoptotic-bodies were: Untreated, $2.00 \pm 0.08 \%$; sevoflurane, $18.0 \pm 0.1 \%$ and DRB, $43.0 \pm 0.2 \%$. The difference between the sevoflurane and untreated groups was considered statistically significant $(\mathrm{P}=0.001, \mathrm{SNK})$ and the DRB group to untreated group was also statistically significant $(\mathrm{P}<0.001$, SNK; Fig. 2).

Sevoflurane increasing DNA damage observed by electrophoresis of DNA. The DNA was digested by specific endonucleases into fragments and ultimately packed into vesicles. DNA integrity in cells exposed to sevoflurane and controls was analyzed by $0.8 \%$ agarose gel electrophoresis. Electrophoresis of DNA isolated from A549 cells following exposure to sevoflurane and control is shown in Fig. 3. A DNA fragment was observed with sevoflurane and DRB group, but not with untreated group.

Sevoflurane provoking caspase 3/7. A specific class of cysteine proteases, termed caspases, are activated in an amplifying proteolytic cascade, including caspase $3 / 7$, which exhibits an important role in cell apoptosis (24). As shown in Fig. 4, the activity of caspase $3 / 7$ on A549 cells of three groupswas as follows: Sevoflurane, 24055.4 \pm 6435.1 ; DRB, 46624.3 \pm 5663.5 and untreated, 6423.6 \pm 3194.7 . Cells treated with sevoflurane exhibited significantly increased levels of caspases $3 / 7$ ( 2.74 times growth) as compared with the untreated cells $(\mathrm{P}<0.001, \mathrm{SNK})$. The DRB-group exhibited a $\sim 6.25$ times increase compared with the untreated group $(\mathrm{P}<0.001, \mathrm{SNK})$. 

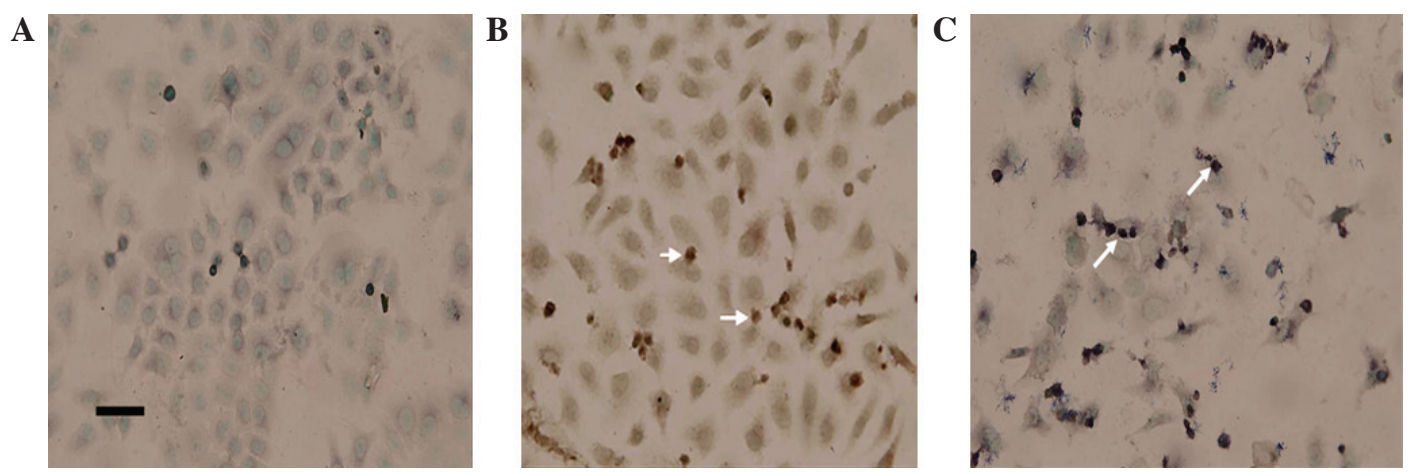

Figure 2. Light microscopy images of A549 cells. (A) Negative control untreated cells. (B) A549 cells following exposure to $1 \mathrm{mM}$ sevoflurane for $2 \mathrm{~h}$. (C) A549 cells following treatment with DRB for $2 \mathrm{~h}$. Cells were considered TUNEL-positive when stained nuclei (brown) were present after staining by diaminobenzidine (DAB). White arrows indicate brown nuclei-positive cells (magnification, $\mathrm{x} 40$; scale bar, $50 \mu \mathrm{m}$ ). Cells of the sevoflurane and DRB groups became spherical, swollen and dispersed into smaller groups and more apoptotic-bodies were observed. The values were obtained from three repeated experiments and ten images per experiment and the averages are presented as the mean \pm standard deviation. DRB, daunorubicin hydrochloride.

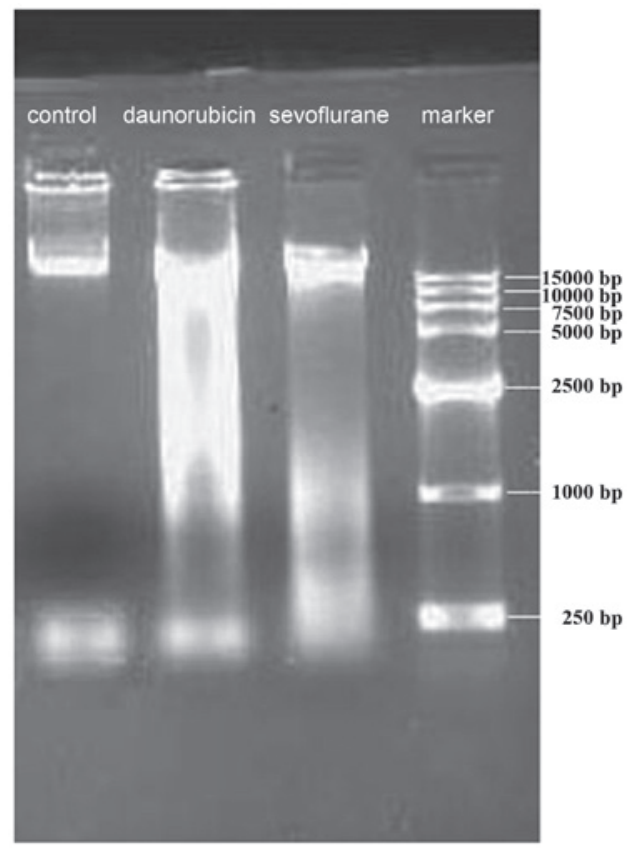

Figure 3. Electrophoresis of DNA from A549 cells following exposure to sevoflurane and control cells. DNA integrality was analyzed by $0.8 \%$ agarose gel electrophoresis. DNA degradation was observed in sevoflurane- and DRB-treated cells, but not in the untreated cells. The data obtained from three experiments for each sample are presented. DRB, daunorubicin hydrochloride.

These data indicate that the activation of caspases $3 / 7$ is involved in sevoflurane-induced cellular injury (Fig. 4).

\section{Discussion}

In this study, 5\% sevoflurane was observed to induce cellular damage and apoptosis of A549 lung alveolar epithelial cells by decreasing cell viability, increasing apoptotic bodies, impairing DNA integrity and provoking caspase $3 / 7$. Sevoflurane, with its low pungency, non-irritating odor and low blood/gas partition coefficient, is a potent novel inhalation anesthetic agent widely used for general anesthesia (25). Although increasing evidence of the noxious effects of volatile anesthetics has attracted attention, particularly for their potential toxic effects following long surgery (25), the potential significant lung epithelial cell
The activity of caspase $3 / 7$

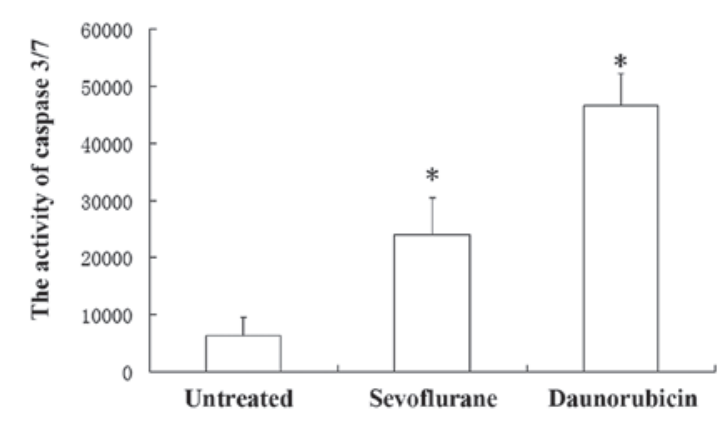

Figure 4. Effect of sevoflurane on intracellular caspase 3/7 activities on A549 cells. A549 cells were incubated in $95 \%$ air and $5 \% \mathrm{CO}_{2}$ for $2 \mathrm{~h}$ with $5 \%$ sevoflurane. Following treatment, $100 \mu \mathrm{l}$ caspase $3 / 7$ substrate was added to the cell suspension. Data represent the intracellular caspase 3/7 activity in the A549 cells. DRB and sevoflurane induced caspase 3/7 activation compared with untreated group. The difference between sevoflurane group and the untreated group was statistically significant $(\mathrm{P}<0.001, \mathrm{SNK})$ and between the DRP group and the untreated group was statistically significant $(\mathrm{P}<0.001$, SNK). The data shown was representative of three independent experiments. Data are shown as the mean \pm standard deviation. ${ }^{*} \mathrm{P}<0.05$, vs. the untreated group. DRB, daunorubicin hydrochloride; SNK, Student-Newman-Keuls.

damage resulting from sevoflurane treatment has not been fully understood. This area of research may contribute to elucidating the role of stress-induced apoptosis in lung diseases following long surgery using volatile anesthetics, including sevoflurane and thus, may be of value in clinical practice.

Previous evidence with regard to apoptotic effects of volatile anesthetics has been conflicting. This may result from differences in study designs, as well as the inherent limitations of in vitro models $(9,10,26,27)$. The difficulties of the various experimental approaches in the literature are associated with the handling of the concentration of volatile agents in vitro. However, after 20 years, significant progress has been made by a number of researchers. Muckter et al (28) reported an apparatus for the exposure of cultured A549 cells to volatile anesthetics in 1998. Matsuoka et al (10) controlled the concentration with the container equipped with two sealing cocks in normal peripheral lymphocytes in vitro in 2001.

In the present study the concentration was monitored in two parallel methods of each test. It is principally feasible to 
test the concentration of effluent gas with infrared spectroscopy and fluid with gas chromatography. The methods ensure not only the concentration of sevoflurane in the air of the tight chamber, but also the liquids that the cells survive in. The data showed that the DMEM medium-gas partition coefficient of sevoflurane determined in this study was $0.38 \pm 0.08$, which was similar with the reports that the coefficient in cells cultured just like the DMEM was 0.36 (10). Therefore, the concentrations of $1.0 \pm 0.1 \mathrm{mM}$ were calculated to be equivalent to $5 \%$ sevoflurane in the gas phase of the DMEM-gas system. Stephanova et al (18) observed that A549 cells treated with halothane at 1.5-3 $\mathrm{mM}$ in vitro induced morphological alererations, as well as DNA damage. The authors also reported that an irreversible impairment of the cell genome is initiated at a concentration as low as $1.5 \mathrm{mM}$, defining the threshold for cell survival (16-18). In the current study, the concentration of $1.0 \pm 0.1 \mathrm{mM}$ of sevoflurane on A549 cells $<1.5 \mathrm{mM}$ of halothane induced apoptosis-like changes by decreasing cell viability, increasing the number of apoptotic bodies, impairing DNA integrity and provoking caspase $3 / 7$. Further study at a lower concentration is required.

In the dead cells, the ATP level was markedly decreased, thus, the ATP levels better reflected the cell viability. The ATP assay is a popular assay and is used to evaluate pharmacological toxicity sensitively and accurately (29). The data indicated that the level of ATP in A549 cells exposed to sevoflurane had decreased compared with the untreated group. This indicated that cell viability of human A549 cells reduced to $52 \%$ following 2-h exposure to $5 \%$ sevoflurane. The DRB group that was used to treat lung cancer reduced to $72 \%$ of A549 cell death. Bakand et al (24) observed that cell viability was reduced in a concentration dependent manner following exposure of human A549 cells to $\mathrm{NH}_{3}$ with ATP assay. However, it remains unkown whether sevoflurane also promotes A549 cell apoptosis in a concentration-dependent manner and the mechanism of apoptosis on A549 cells induced by sevoflurane is unknown.

The number of remaining cells treated with sevoflurane was reduced compared with the untreated group but not all cells swelled and detached from the subculture. Apoptotic bodies may be observed by a TUNEL assay via a light microscope. These results were consistent with the ATP assay results that showed that A549 cells exposed to sevoflurane underwent programmed cell death. Information of the noxious effects of volatile anesthetics and the apoptosis of peripheral polymorphonuclear neutrophils (26), T lymphocytes, natural killer cells, colon carcinoma and larynx carcinoma (HEP-2) have been previously reported $(10,30,31)$. Apoptotic events in type II pneumocytes are usually accompanied with severe pulmonary complications. Clinical studies have provided data that apoptotic cells are observed in humans during the resolution phase following acute lung injury (32). Thus, clarifying the mechanism that induced cell death may contribute to the understanding of chronic or temporary disorders following inhalation anesthesia (14). However, investigations in vivo are usually more complex and clinical experiments or animal experiments of the adverse effects of volatile anesthetics are required in the future.

Studies have highlighted the cyto- and genotoxic effect of anesthetics in a series of model systems in vitro (16,33-43).
As apoptotic morphology was observed, the fragmentation of genomic DNA that usually represented a critical event in cell cycle and may lead to cell death was investigated. The current data showed DNA fragmentation in A549 cells treated with sevoflurane, even at a concentration of $1.0 \pm 0.1 \mathrm{mM}$, without a ladder pattern of fragments. These data were in agreement with the in vitro genotoxic effect of inhalation anesthetics on human lymphocytes (43). Hacker et al (41) observed a phenomenon associated with DNA cleavage and degradation of nuclear lamina by caspase 3 during apoptosis. The results aided in the explanation that sevoflurance-induced apoptosis in cells by DNA degradation may lead to caspase-dependent signaling events; however, the potential genotoxic mechanism remains unclear.

The caspase family of cysteine proteases is the central mediator of the proteolytic cascade leading to cell death and elimination of compromised cells $(33,34)$. Caspase 3 is key in apoptosis. A previous study demonstrated that caspase 3/7 activation is an important step in glutathione depletion-induced apoptosis in resting and inflammatory neutrophils (10). The current data showed that the percentage of caspase $3 / 7$ activity of A549 increased following exposure to sevoflurane. This result suggested that caspase $3 / 7$ may be involved in the apoptosis of A549 following exposure to sevoflurane for $2 \mathrm{~h}$, however, further investigations are required to determine the precise pathway. Furthermore, a previous study observed that sevoflurane may induce caspase 3/7 activation and increase amyloid- $\beta$ levels in H4-APP cells and key changes associated with Alzheimer's disease neuropathogenesis (36). Therefore, sevoflurane-induced caspase 3 activation indicated that induced alterations in apoptosis processing were, at least partially, dependent upon caspase activation. Roesslein et al (27) observed that $8 \%$ sevoflurane $(1,170 \mu \mathrm{mol} / \mathrm{l})$ is a specific activator of the apoptotic signal p38 MAP kinase cascade by incubating Jurkat T cells with $8 \%$ sevoflurane for $24-\mathrm{h}$ treatment. That signal appears to act as a proapoptotic intermediate and multifunctional stress-sensing kinase through mitochondrial-dependent caspase activation and is required for apoptosis induced by oxidative stress, tumor necrosis factor and endoplasmic reticulum stress (44-46). Thus, it is possible that sevoflurane may activate the p38 MAP kinase pathway of apoptosis with caspase 3/7 activation in A549 lung cells in vitro. A number of the results may be a consequence of the cancer cell character. However, it is crucial to perform the same experiments in primary rats or mice cultures of this cell type to verify the current findings. In the future, studies of the mechanism of p38 MAPK caspase apoptosis in lung alveolar cells lower concentrations of sevoflurane in vivo are required.

No data are available concerning the mechanism of apoptosis in sevoflurane lung cytotoxicity. A number of experimental data have revealed sevoflurane's parent molecule, halothane, increased the cytosolic concentration of $\mathrm{Ca}^{2+}$, where calcium acts as an essential signal by releasing cytochrome $\mathrm{c}$ and other factors, provoking apoptosis of cells $(47,48)$. Significant disturbances in the function and conformation of the $\mathrm{Ca}^{2+}$-ATPase were also reported for volatile anesthetics applied at clinically relevant concentrations (49). However, it is difficult to assess in vivo whether sevoflurane or surgical stress are the primary cause of the lung tissue damage and cell apoptosis. Experimental support for this hypothesis is required. 
In conclusion, the results of the present study suggest that $1 \mathrm{mM}$ sevoflurane exerts an apoptotic effect on the A549 lung alveolar epithelial cells in vitro by decreasing cell viability, increasing apoptotic body formatiom, impairing DNA integrity and activating caspase $3 / 7$. The exact mechanism of the effect of sevoflurane on alveolar cells is not well understood and further studies are required to specify the signaling pathways involved. The current findings may ultimately contribute to recognizing the role of lung injury in diseases following a long surgery under sevoflurane anesthesia, which is likely to facilitate the design of safe anesthetics and improved anesthesia care for patients. Taking into consideration that sevoflurane may modulate respiratory function, its use in susceptible patients should be avoided.

\section{Acknowledgements}

The authors would like to thank Yun-Xia Zuo and Guo-Hua Li (Professor of Laboratory of Anesthesiology and Critical Care Medicine, West China Hospital, Sichuan University, Chengdu, China) for their scientific discussions for this study. This study was supported by a grant from WJTU11BR071 (Southwest Jiaotong University One Hundred Young Teachers project Fund, Chengdu, China).

\section{References}

1. Tang J, Eckenhoff MF and Eckenhoff RG: Anesthesia and the old brain. Anesth Analg 110: 421-426, 2010.

2. Terrando N, Brzezinski M, Degos V, Eriksson LI, Kramer JH, Leung JM, Miller BL, Seeley WW, Vacas S, Weiner MW, et al: Perioperative cognitive decline in the aging population. Mayo Clin Proc 86: 885-893, 2011.

3. Wu X, Lu Y, Dong Y, Zhang G, Zhang Y, Xu Z, Culley DJ, Crosby G, Marcantonio ER, Tanzi RE and Xie Z: The inhalation anesthetic isoflurane increases levels of proinflammatory TNF- $\alpha$, IL-6, and IL-1 $\beta$. Neurobiol Aging 33: 1364-1378, 2012.

4. Xie Z and Tanzi RE: Alzheimer's disease and post-operative cognitive dysfunction. Exp Gerontol 41: 346-359, 2006.

5. Xu Z, Dong Y, Wu X, Zhang J, McAuliffe S, Pan C, Zhang Y, Ichinose $\mathrm{F}$, Yue $\mathrm{Y}$ and $\mathrm{Xie} \mathrm{Z}$ : The potential dual effects of anesthetic isoflurane on $\mathrm{A} \beta$-induced apoptosis. Curr Alzheimer Res 8: 741-752, 2011.

6. Lu Y, Wu X, Dong Y, Xu Z, Zhang Y and Xie Z: Anesthetic sevoflurane causes neurotoxicity differently in neonatal naive and Alzheimer disease transgenic mice. Anesthesiology 112: 1404-1416, 2010.

7. Pollock RE, Lotzová E and Stanford SD: Surgical stress impairs natural killer cell programming of tumor for lysis in patients with sarcomas and other solid tumors. Cancer 70: 2192-2202, 1992.

8. Salo M: Effects of anaesthesia and surgery on the immune response. Acta Anaesthesiol Scand 36: 201-220, 1992

9. Loop T, Dovi-Akue D, Frick M, Roesslein M, Egger L, Humar M, Hoetzel A, Schmidt R, Borner C, Pahl HL, et al: Volatile anesthetics induce caspase-dependent, mitochondria-mediated apoptosis in human T lymphocytes in vitro. Anesthesiology 102 $1147-1157,2005$.

10. Matsuoka H,Kurosawa S, Horinouchi T, Kato M and Hashimoto Y: Inhalation anesthetics induce apoptosis in normal peripheral lymphocytes in vitro. Anesthesiology 95: 1467-1472, 2001.

11. Delogu G, Moretti S, Famularo G, Antonucci A, Signore L, Marcellini S, Lo Bosco L and De Simone C: Circulating neutrophils exhibit enhanced apoptosis associated with mitochondrial dysfunctions after surgery under general anaesthesia. Acta Anaesthesiol Scand 45: 87-94, 2001.

12. Lalchev ZI: Surface properties of lipids and proteins at bio-interfaces. In: Handbook of Surface and Colloid Chemistry. Birdi KS (ed). CRC Press, New York, NY, pp:625-687, 1997.

13. White MK, Baireddy V and Strayer DS: Natural protection from apoptosis by surfactant protein A in type II pneumocytes. Exp Cell Res 263: 183-192, 2001.
14. Fehrenbach H: Alveolar epithelial type II cell: defender of the alveolus revisited. Respir Res 2: 33-46, 2001.

15. Watanabe N, Dickinson DA, Krzywanski DM, Iles KE, Zhang H, Venglarik CJ and Forman HJ: A549 subclones demonstrate heterogeneity in toxicological sensitivity and antioxidant profile. Am J Physiol Lung Cell Mol Physiol 283: L726-L736, 2002.

16. Topouzova-Hristova T, Daza P, Garcia-Herdugo G and Stephanova E: Volatile anaesthetic halothane causes DNA damage in A549 lung cells. Toxicol In Vitro 20: 585-593, 2006.

17. Topouzová-Hristova T, Hazarosova R, Bandreva B and Stephanova E: Halothane does not directly interact with genome DNA of A549 cells. Folia Biol (Praha) 53: 176-182, 2007.

18. Stephanova E, Topouzova-Hristova T and Konakchieva R: Mitochondria are involved in stress response of A549 alveolar cells to halothane toxicity. Toxicol In Vitro 22: 688-694, 2008.

19. Oka M, Hirazawa K, Yamamoto K, Iizuka N, Hazama S, Suzuki T and Kobayashi N: Induction of Fas-mediated apoptosis on circulating lymphocytes by surgical stress. Ann Surg 223: 434-440, 1996

20. Sasajima K, Inokuchi K, Onda M, Miyashita M, Okawa KI, Matsutani T and Takubo K: Detection of T cell apoptosis after major operations. Eur J Surg 165: 1020-1023, 1999.

21. Lieber M, Smith B, Szakal A, Nelson-Rees W and Todaro G: A continuous tumor-cell line from a human lung carcinoma with properties of type II alveolar epithelial cells. Int J Cancer 17: 62-70, 1976.

22. Elmore S: Apoptosis: a review of programmed cell death. Toxicol Pathol 35: 495-516, 2007.

23. Petty RD, Sutherland LA, Hunter EM and Cree IA: Comparison of MTT and ATP-based assays for the measurement of viable cell number. J Biolumin Chemilumin 10: 29-34, 1995.

24. Bakand S, Winder C and Hayes A: Comparative in vitro cytotoxicity assessment of selected gaseous compounds in human alveolar epithelial cells. Toxicol In Vitro 21: 1341-1347, 2007.

25. Ghatge S, Lee J and Smith I: Sevoflurane: an ideal agent for adult day-case anesthesia? Acta Anaesthesiol Scand 47: 917-931, 2003.

26. Wong CH, Liu TZ, Chye SM, Lu FJ, Liu YC, Lin ZC and Chen CH: Sevoflurane-induced oxidative stress and cellular injury in human peripheral polymorphonuclear neutrophils. Food Chem Toxicol 44: 1399-1407, 2006.

27. Roesslein M,Frick M, Auwaerter V,Humar M, Goebel U, Schwer C, Geiger KK, Pahl HL,Pannen BH and Loop T: Sevoflurane-mediated activation of p38-mitogen-activated stresskinase is independent of apoptosis in Jurkat T-cells. Anesth Analg 106: 1150-1160, 2008.

28. Mückter H, Zwing M, Bäder S, Marx T, Doklea E, Liebl B, Fichtl B and Georgieff M: A novel apparatus for the exposure of cultured cells to volatile agents. J Pharmacol Toxicol Methods 40: 63-69, 1998.

29. Lundin A and Thore A: Analytical information obtainable by evaluation of the time course of firefly bioluminescence in the assay of ATP. Anal Biochem 66: 47-63, 1975.

30. Loop T, Scheiermann P, Doviakue D, Musshoff F, Humar M, Roesslein M, Hoetzel A, Schmidt R, Madea B, Geiger KK, et al: Sevoflurane inhibits phorbol-myristate-acetate-induced activator protein-1 activation in human T lymphocytes in vitro: potential role of the p38-stress kinase pathway. Anesthesiology 101: 710-721, 2004

31. Kvolik S, Glavas-Obrovac L, Bares V and Karner I: Effects of inhalation anesthetics halothane, sevoflurane, and isoflurane on human cell lines. Life Sci 77: 2369-2383, 2005.

32. Bardales RH, Xie SS, Schaefer RF and Hsu SM: Apoptosis is a major pathway responsible for the resolution of type II pneumocytes in acute lung injury. Am J Pathol 149: 845-852, 1996.

33. Nicholson DW: Caspase structure, proteolytic substrates, and function during apoptotic cell death. Cell Death Differ 6: 1028-1042, 1999 .

34. Earnshaw WC, Martins LM and Kaufmann SH: Mammalian caspases: structure, activation, substrates, and functions during apoptosis. Annu Rev Biochem 68: 383-424, 1999.

35. O'Neill AJ, O'Neill S, Hegarty NJ, Coffey RN, Gibbons N, Brady H, Fitzpatrick JM and Watson RW: Glutathione depletion-induced neutrophil apoptosis is caspase 3 dependent. Shock 14: 605-609, 2000.

36. Dong Y, Zhang G, Zhang B, Moir RD, Xia W, Marcantonio ER, Culley DJ, Crosby G, Tanzi RE and Xie Z: The common inhalational anesthetic sevoflurane induces apoptosis and increases beta-amyloid protein levels. Arch Neurol 66: 620-631, 2009.

37. Molliex S, Dureuil B, Aubier M, Friedlander G, Desmonts JM and Clerici C: Halothane decreases Na,K-ATPase, and $\mathrm{Na}$ channel activity in alveolar type II cells. Anesthesiology 88: 1606-1613, 1998. 
38. Sardas S, Aygün N, Gamli M, Unal Y, Unal N, Berk N and Karakaya AE: Use of alkaline comet assay (single cell gel electrophoresis technique) to detect DNA damages in lymphocytes of operating room personnel occupationally exposed to anaesthetic gases. Mutat Res 418: 93-100, 1998.

39. Jaloszyński P, Kujawski M, Wasowicz M, Szulc R and Szyfter K: Genotoxicity of inhalation anesthetics halothane and isoflurane in human lymphocytes studied in vitro using the comet assay. Mutat Res 439: 199-206, 1999.

40. Patel AB, Sokolowski J, Davidson BA, Knight PR and Holm BA Halothane potentiation of hydrogen peroxide-induced inhibition of surfactant synthesis: the role of type II cell energy status. Anesth Analg 94: 943-947, 2002.

41. Häcker G: The morphology of apoptosis. Cell Tissue Res 301: 5-17, 2000.

42. Valtcheva R, Stephanova E, Jordanova A, Pankov R, Altankov G and Lalchev Z: Effect of halothane on lung carcinoma cells A 549. Chem Biol Interact 146: 191-200, 2003.

43. Szyfter K, Szulc R, Mikstacki A, Stachecki I, Rydzanicz M and Jaloszyński P: Genotoxicity of inhalation anaesthetics: DNA lesions generated by sevoflurane in vitro and in vivo. J Appl Genet 45: 369-374, 2004.

44. Kanamoto T, Mota M, Takeda K, Rubin LL, Miyazono K, Ichijo H and Bazenet CE: Role of apoptosis signal-regulating kinase in regulation of the c-Jun $\mathrm{N}$-terminal kinase pathway and apoptosis in sympathetic neurons. Mol Cell Biol 20: 196-204, 2000.
45. Hofmann TG, Möller A, Hehner SP, Welsch D, Dröge W and Schmitz ML: CD95-induced JNK activation signals are transmitted by the death-inducing signaling complex (DISC), but not by Daxx. Int J Cancer 93: 185-191, 2001.

46. Hatai T, Matsuzawa A, Inoshita S, Mochida Y, Kuroda T, Sakamaki K, Kuida K, Yonehara S, Ichijo H and Takeda K: Execution of apoptosis signal-regulating kinase 1 (ASK1)-induced apoptosis by the mitochondria-dependent caspase activation. J Biol Chem 275: 26576-26581, 2000.

47. Rithalia A, Qureshi MA, Howarth FC and Harrison SM: Effects of halothane on contraction and intracellular calcium in ventricular myocytes from streptozotocin-induced diabetic rats. Br J Anaesth 92: 246-253, 2004.

48. Yu WF, Yang LQ, Zhou MT, Liu ZQ and Li Q: $\mathrm{Ca}^{2+}$ cytochemical changes of hepatotoxicity caused by halothane and sevoflurane in enzyme-induced hypoxic rats. World J Gastroenterol 11: 5025-5028, 2005

49. Lopez MM and Kosk-Kosicka D: How do volatile anesthetics inhibit $\mathrm{Ca}(2+)$-ATPases? J Biol Chem 270: 28239-28245, 1995. 